\title{
Análisis del contenido visual en la cobertura informativa del virus SARS-CoV-2 y la Covid-19 en las revistas de divulgación científica españolas en el entorno digital
}

\section{Analysis of visual content in SARS-CoV-2 and Covid-19 news coverage of scientific divulgation in Spanish magazines in the digital environment}

Recibido: $14 / 08 / 2020$

Aceptado: 16/11/2020

Publicado: 30/11/2020
Aida María De Vicente Domínguez aidamaria@uma.es http://orcid.org/0000-0002-8085-5097

Universidad de Málaga (España)

Mireya Rocío Carballeda mcarballeda@uma.es https://orcid.org/0000-0002-5269-2489

Universidad de Málaga (España)

Resumen: Se analiza el contenido visual en la cobertura del COVID-19 en las ediciones digitales de las revistas de divulgación científicas españolas más consumidas durante esta crisis epidemiológica. Los objetivos son analizar la presencia, tipología, hipervínculos y autoría de la imagen en las piezas informativas. Se analiza la imagen $(n=549)$ en las piezas publicadas en muyinteresante.es $(n=204)$ y nationalgeographic.com.es $(N=85)$ desde el 7 de febrero al 14 de mayo de 2020. Se opta por un análisis de contenido estableciendo previamente unos códigos de identificación de las variables objeto de estudio. Se concluye que no se usa la potencialidad del contenido visual en el entorno digital y se aportan propuestas de mejora para optimizarlo por su importancia como fuente de conocimiento durante una crisis sanitaria. 
Palabras clave: Contenido visual, Divulgación científica, COVID-19, Crisis sanitaria, Imagen, Comunicación, Revistas.

Abstract: The visual content in the coverage of COVID-19 in the digital editions of the most consumed Spanish scientific journals during this epidemiological crisis is analyzed. The objectives are to analyze the presence, number, typology, hyperlink and authorship of the image in the informative pieces. The image $(n=549)$ is analyzed in the informative pieces published in muyinnteresante.es $(n=204)$ and nationalgeographic.com.es $(N=85)$ from February 7 to May 14, 2020. A content analysis was chosen by previously established codes to identify the variables under study. It is established that the potential of the image is not used in the digital environment and proposals for improvement are made to optimize the potential of the image due to its importance as a source of knowledge in times of health crisis.

Key words: Visual content, Scientific divulgation, COVID-19, Health crisis, Image, Communication, Magazines.

\section{Introducción}

La función que deben cumplir los medios de comunicación en la información sanitaria es que la población reciba mensajes e informaciones educativas que permitan la sensibilización para que, de este modo, se pueda de forma eficaz, adoptar conocimientos, actitudes y prácticas sobre la situación (Ramírez et al., 2010). La imagen puede jugar un papel importante en la consecución de estos objetivos al ser un recurso óptimo para explicar, mostrar, incidir y hacer comprensible un acontecimiento. Tómese como referente su eficacia en crisis precedentes como la del ébola: Alcibar (2018) comprobó que la visualización fue un factor clave en la popularización de los aspectos técnico-biomédicos de la epidemia.

La imagen, además, junto al titular es lo primero que capta la atención de la audiencia fomentando o frenando el acceso a la lectura de la pieza informativa. Si Trujillo \& Contreras (2002) ya indicaban hace casi dos décadas que la imagen es más del agrado del usuario que el texto descriptivo, ya que la información visual ofrece más rápidamente todos los detalles, los informes actua- 
les concluyen que el contenido visual, se erige entre las principales preferencias de consumo informativo de las audiencias. Datos que los propios medios de comunicación han confirmado durante la cobertura del COVID-19: el diario El País desvela que lo más leído en la crisis del coronavirus es la información visual y que la pieza informativa "más vista en la historia de The Washington Post es un gráfico que simula escenarios de expansión del virus según el grado de distanciamiento social" (Yarnoz, 2020). En este contexto, dada la importancia que la imagen tiene en la atracción y consumo de una pieza informativa, así como, en la comprensión de los contenidos, se analiza su uso y valor informativo en la cobertura informativa de las crisis del virus SARS-CoV-2.

Un recurso que ha sido recomendado tanto por la Organización Panamericana de la Salud, la organización First Draft (2020), cuya misión es recopilar y facilitar recursos de verificación esenciales para periodistas, y la Organización Mundial de la Salud (OMS). Las cuestiones que nos planteamos son las siguientes: ¿Se hace uso de las nuevas tecnologías para contextualizar, documentar y visionar la información?, ¿se informa usando la imagen como interfaz principal o acompañando al texto informativo?, ¿cuál es la tipología más representativa? y ¿cuál es la procedencia de las imágenes? Una investigación no realizada hasta el momento.

Los estudios precedentes que han analizado el contenido visual en la cobertura de las crisis sanitarias a nivel nacional e internacional, se han centrado principalmente, en la cobertura de la crisis del ébola. Catalán (2014) analiza la imagen usada al inicio de esta crisis en España investigando su tipología (fotografía, gráfico, infografía, dibujo, mapa, tabla), encuadre, posición, tamaño, y distribución del contenido visual durante los primeros días de la crisis en la prensa impresa española de referencia. Welhausen (2015) aborda las estrategias visuales usadas en cuatro infografías creadas por The New York Times para comunicar el riesgo del Ébola. Alcibar (2018) explora el papel que jugó la visualización en la popularización de los aspectos técnico-médicos analizando los gráficos que aparecieron en cinco periódicos estudiando la proporción e idoneidad de la información, el contenido técnico-biomédico, la estructura sintáctica adoptada en los titulares y las fuentes de las que se sirven los periodistas para adquirir los contenidos visuales.

La presencia y función del contenido visual también se ha analizado en otras crisis sanitarias. Wong et al. (2013) comparó los efectos de presentar la ame- 
naza de la gripe H1N1, en la propagación e intención de buscar información adicional por los usuarios, en dos formatos visuales: a través de un mapa interactivo (modo visual) versus el uso de palabras y de números (modo numérico). Significativo es el estudio de Shin (2016) que compara 254 infografías de seis crisis epidémicas (ébola, SRAS, MERS, H1N1, Gripe aviar y Zika) creadas por las organizaciones de salud y los medios de comunicación.

Otros estudios han investigado el contenido visual con un enfoque colateral porque no es el objeto principal del estudio. Es el caso de Camacho (2009) que analizó el tipo de imagen más usada en la cobertura del virus de influenza A (H1/N1) en el tratamiento informativo que ofreció la prensa española durante la primera semana de cobertura; López Villafranca $(2012,2013)$ que comprueba la asociación entre imágenes y palabras clave para construir un determinado encuadre en la gripe A y la bacteria E. Coli; así como el encuadre, autoría de la pieza visual, tipología de la imagen, plano usado y modalidad de pie de foto (descriptivo o identificativo) en la crisis generada por la bacteria E. Coli.

Estos estudios indican que, si bien, ha sido objeto de interés para la comunidad científica, en el caso de los medios de comunicación españoles se han centrado en los formatos impresos de los principales periódicos de referencia. De su presencia en los formatos digitales destaca el estudio de Costa-Sánchez et al. (2015) centrado en las posibilidades transmedia de los medios en el brote del Ébola de 2014 aunque analiza colateralmente la imagen, junto a otras variables. El estudio de Marín \& Armentia (2002) que hace referencia a cómo El Periódico de Catalunya y El País en el 2002 experimentaron con la tecnología flash para informar de la crisis de las "vacas locas".

Ahora, el presente estudio pretende aportar nuevos datos a esta línea de investigación analizando el contenido visual en la cobertura de la información en España durante el COVID-19 en las revistas de divulgación científica, y que hasta el momento ha sido abordado desde tres perspectivas. Andreu-Sánchez \& Martín-Pascual (2020) investigan la imagen falsa en las piezas visuales publicadas en Internet, analizando si son fotografías o ilustraciones, en blanco y negro o en color, en 2 o 3 dimensiones y sus fuentes de origen u autoría; Bravo et al. (2020) analizan las estrategias empleadas por el caricaturista Bonil para advertir a los ecuatorianos sobre la gravedad del COVID-19 (contagios, fallecimientos, protección, medicación, violencia familiar) concluyendo que 
el humor periodístico sirvió de herramienta para construir una convicción colectiva de unidad frente a la adversidad. Pérez Daza (2020) aborda la estética visual de la pandemia usada en diversos sectores (como el artístico, el publicitario y el periodístico), mostrando algunas de las imágenes proyectadas en las portadas de los medios de comunicación del COVID-19.

Junto a estos estudios se destacan los proyectos de investigación en curso. El grupo Neuro-com (2020), del Departamento de Comunicación Audiovisual y Publicidad de la Universidad Autónoma de Barcelona y el Instituto de Radio Televisión Española, con la participación del Institut de Recerca de l'Esport (IRE) de la mencionada universidad, están investigando la percepción y emoción de la ciudadanía sobre las imágenes que se utilizan para ilustrar el coronavirus SARS-CoV-2 causante del COVID-19, en diversos medios.

En esta investigación, se analizan las revistas de divulgación científica más consumidas durante la crisis del coronavirus porque han superado en cuotas de audiencia incluso a la prensa de referencia española. Si estudios precedentes analizan la función informativa desempeñada por la prensa de referencia (por ser la fuente principal de información en tiempos de crisis), estas revistas también han sido una fuente de conocimiento por su alta audiencia y aún no han sido investigados sus patrones en la construcción del mensaje periodístico visual.

En ese sentido, se analiza la presencia y tipología de la imagen, pues su diseño y presentación tiene efectos en la atención de los espectadores (Smeesters \& Mandel, 2006). Como indica Cairo (2013) las modalidades para hacer comprensible la información pueden ser variadas, desde gráficos figurativos (ilustraciones, fotografías, dibujos, diagramas, mapas, etc.) hasta gráficos no figurativos (gráficos estadísticos o visualizaciones de datos).

El estudio también analiza si se usan las nuevas tecnologías para contextualizar y añadir documentación a la imagen mediante hipervínculos. Una contextualización necesaria para anclar el significado de las imágenes porque suelen ser polisémicas y susceptibles de interpretación. Una práctica que en los medios impresos se realiza mediante un mensaje lingüístico en el pie de foto. Si "un pie bien escrito hace que la imagen sea inmediatamente entendible" (Harrower, 2002, p. 59) un buen uso de los recursos digitales permite añadir más información, visualizarla con más detalle, e incluso convertir a la 
imagen en el soporte comunicativo o interfaz único para contar una historia. Una combinación de elementos icónicos y visuales que son considerados óptimos en la cobertura de las crisis sanitarias. Catalán (2019) afirma como las imágenes ligadas a "textos o conversaciones pueden aumentar la atención o el recuerdo de la información sanitaria, así como la comprensión, especialmente en personas con bajo alfabetismo" (p. 131). Alcibar (2018) destaca como principal potencialidad de esta combinación "ofrecer un mayor poder explicativo que las simples palabras e imágenes por sí mismas" (p. 367). Welhausen (2015) recomienda incluir texto explicativo y/u objetos visuales para contextualizar más completamente la visualización de datos.

El estudio se complementa investigando las fuentes o procedencia de las imágenes. Y es que, si un buen periodismo depende de las fuentes usadas para calcular su rigurosidad y veracidad para construir el mensaje periodístico en la pieza informativa, igual de relevante son las fuentes que han proporcionado a los profesionales de la información las representaciones visuales. Un estudio que pretende profundizar en la literatura sobre los contenidos visuales en la cobertura de la información epidémica pues en un estado de emergencia la rigurosidad, contextualización y comprensión, adquiere máxima importancia para frenar la curva epidemiológica.

\section{Objetivos y metodología}

El estudio parte de las siguientes hipótesis: elevada presencia de contenido visual pero principalmente de la imagen fija frente a la audiovisual para informar sobre lo concerniente al COVID-19, siendo la fotografía la tipología principal (H1); un contenido visual, conformado principalmente por una imagen, que no suele ser producida por el medio sino que procede de banco de imágenes, por lo que tienen una función más ilustrativa que informativa (H2); escaso uso de la imagen como interfaz o soporte principal predominando la información en el soporte textual (H3); y casi nulo aprovechamiento de los recursos digitales para añadir documentación a la imagen (H4).

El objetivo general de la investigación es analizar el contenido visual en las piezas informativas publicadas en las revistas de divulgación científica editadas en España para informar del virus SARS-Cov-2 y el COVID-19. Y los objetivos generales son: 
- Analizar la presencia de la imagen en la cobertura mediática sobre lo concerniente a la Covid-19.

- Identificar las tipologías visuales más representativas.

- Averiguar si la imagen acompaña al texto o es el soporte e interfaz principal.

- Investigar si se usan las nuevas tecnologías para documentar el contenido y mejorar la visualización.

- Dar a conocer la autoría o las fuentes de las que se sirven las revistas de divulgación científica para el contenido visual.

Y la metodología empleada para el estudio se ha estructurado en los siguientes pasos:

- Búsqueda en bases de datos nacionales e internacionales con las siguientes ecuaciones de búsqueda en inglés y en español: imagen, contenido visual, visualización y periodismo visual. Cada concepto se combina con las siguientes palabras clave: "crisis sanitaria", "coronavirus", "COVID-19" y "SARS-CoV-2".

- Selección del medio y de la muestra: los medios analizados son las ediciones digitales de las revistas de divulgación científica Muy Interesante y National Geographic, porque son las más leídas durante el periodo objeto de estudio al ocupar los primeros puestos entre las revistas mensuales más consumidas según los datos de EGM (2020). Y las piezas informativas que conforman la unidad de análisis son todas las publicadas en la sección "coronavirus" de ambas ediciones web desde la primera publicación el 7 de febrero al 14 de mayo de 2020 (3 meses) en National Geograhic $(\mathrm{n}=85)$ y Muy Interesante $(n=204)$.

- Bloque de análisis: elaborado con el programa Excel para realizar el análisis estadístico de las variables del estudio (presencia, tipología, interactividad, autoría) con los siguientes códigos de análisis:

- Para investigar la presencia o ausencia de imágenes en la cobertura de la crisis sanitaria se aplica un sistema binomial (SI/NO) a cada una unidad de análisis objeto de estudio. Y para la cantidad de imágenes que conforma cada pieza informativa usada se anali- 
za primero si inserta una imagen otorgándole el código numérico 1 o varias otorgándole un 2.

- Para analizar la tipología de las imágenes atendemos a las dos variantes de la imagen narrativa que son la icónica (imagen fija) y la sonora o audiovisual (video) otorgando un 1 a la imagen fija y un 2 a la imagen audiovisual. Y posteriormente se analiza la modalidad usada de imagen fija y en movimiento. Para la imagen fija se establece la siguiente categoría: 1. ilustración, 2. obras de arte, 3. cómic, 4. fotografía, 5. imagen microscopio, 6. mapa, 7. infografía, 8. 2D, 9. 3D, 10. fotomontaje, 11. otros. Y para la imagen en movimiento o el video estas tres categorías: 1. estático, 2. dinámico o 3. combinación de ambos.

- Para analizar si la imagen acompaña al texto o bien es el soporte principal, se otorga un 1 a la imagen que acompaña al texto y un 2 a la imagen como elemento principal. Y para el análisis de los hipervínculos de la imagen se establece también un código para la identificación del tipo de interactividad: 1. enlaces a otra página; 2. acceder a tabla de datos; 3. desplazamiento 3D y panorámico. 4. desplazamiento por imagen. 5. pantalla completa. 6. vista inicial 7. ampliar/reducir. 8. otros.

- Para investigar las autorías se procede a otorgar un 1 a la imagen identificada y un 2 a la que no tiene identificación. Y con posterioridad se analiza el tipo de fuentes usadas en su globalidad, y para ello se establece el siguiente código de codificación de fuentes visuales: 1 banco de imágenes; 2. agencias. 3. firma propia. 4. otros medios (medios de comunicación, blog); 5. fuentes expertas (revistas especializadas, universidades, organizaciones, centros de investigación, museos, sociedades de investigación). 6. Ministerios 7. Buscadores; 8. Otros (publicidad, etc.). Posteriormente, se procede a realizar la correlación entre autoría y tipología.

- Discusión y conclusiones. 


\section{Resultados}

\subsection{Presencia y tipología de la imagen}

Los resultados desvelan que ambas revistas han publicado contenido visual en el $100 \%$ de las unidades de análisis que informan sobre el virus SARSCov2 $(n=289)$ y que el contenido visual asciende a 549 imágenes, con una media de 1,57 imágenes en muyinteresante.es y de 2,78 en nationalgeographic.com.es. El análisis del número de imágenes usadas por pieza informativa desvela que la variedad de imágenes para la construcción del mensaje informativo es escasa, existiendo una clara preferencia por la imagen única tanto en muyinteresante.es (85\%) como en nationalgeographic.com.es (66\%). Cuando usan varias imágenes la edición digital de National Geographic por orden decreciente suele insertar: 2 imágenes (12\%), 10 o más imágenes (7\%), 9 imágenes (4\%), 3 imágenes (3\%), 4 imágenes (3\%), 5 imágenes (2\%), y 6, 7 y 8 imágenes en un 1\%. Y el análisis en la edición digital de Muy interesante indica que usan en orden decreciente: 2 imágenes (9\%), 10 o más imágenes (5\%), 3 imágenes (3\%) o 4 imágenes (1\%).

Unas imágenes que tienden a ser, según indican los datos, imágenes fijas frente a las audiovisuales: en nationalgeographic.como.es tan sólo hay video en el $4 \%$ y en muyinteresante.es en un 12\%. Es así, que la imagen fija es la principal tipología en ambas revistas con un $82 \%$ en muyinteresante.es y un $96 \%$ en nationalgeographic.com.es.

Atendiendo a la tipología visual más representativa, la imagen fija, los datos indican que es la fotografía con un $73 \%$ en Muy Interesante y un $68 \%$ en National Geographic. El resto de imágenes usadas, por orden decreciente, en la edición digital de Muy Interesante son: ilustración (19\%), 3D (6\%); gráfico (5\%); mapa (1\%) e imagen microscópica (1\%). Y en la edición web de la revista National Geographic: imagen microscópica (16\%); mapa (9\%) e ilustración (7\%).

En el caso de la tipología audiovisual, los datos desvelan que los videos de Muy interesante son un $61 \%$ dinámicos, un $16 \%$ estáticos, y un $23 \%$ combinados; y en National Geographic un $80 \%$ dinámicos y un $10 \%$ estáticos. 


\section{Figura 1}

Tipologías de las imágenes usadas para informar del COVID-19
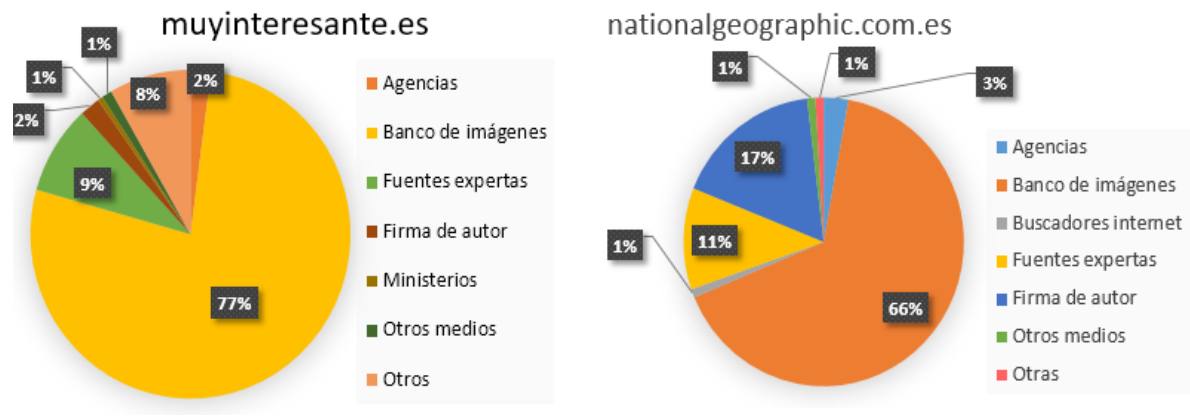

Nota: Elaboración propia.

De estos datos, se destaca que en el periodo objeto de estudio no se usa la infografía: este último un género que es considerado muy efectivo por su valor comunicativo en la información sanitaria. La organización Panamericana de la Salud, en su guía para informar sobre el COVID-19 (OPS, 2020), resalta su efectividad para explicar con facilidad un tema complejo y la organización First Draft (2020) recomienda su uso para explicar los hechos y dar consejos sobre los pasos que las personas pueden tomar. Así como, desde el sector académico también se desvela su potencialidad desde hace décadas: Calvo Hernando (1992) o Trujillo \& Contreras (2002) lo consideraban óptimo para entender conceptos con menor dificultad. Sin embargo, tan solo se usa en una pieza informativa de Muy Interesante.

\subsection{Hipervínculos: contextualización y visualización}

Los resultados indican un uso nulo de hipervínculos en Muy interesante y escaso (7\%) en National Geographic. Se desvela que los tipos de interactividad usados por la revista National Geographic por orden decreciente han sido: enlace a otra página (52\%), desplazamiento 3D y panorámico $(9 \%)$, desplazamiento por imagen (9\%), pantalla completa (9\%), vista inicial (9\%), ampliar/reducir (8\%) y acceder a tabla de datos (4\%). Así, los datos indican que se hace principalmente uso de los recursos para mejorar la visibilidad de la imagen frente a los contextuales, ofreciendo la posibilidad de ampliar la imagen o de desplazarse a través de la pieza visual en diversos formatos (panorámico, 3D, etc.). Se destaca que, aunque en un 52\% se use el enlace a 
otra página este no cumple la función de documentar o añadir documentación a la pieza informativa. Además, no hay enlaces dentro de la pieza informativa inicial para explicar detalles.

\section{Figura 2}

Representatividad del uso de la interactividad / Hipervínculos en las piezas informativas

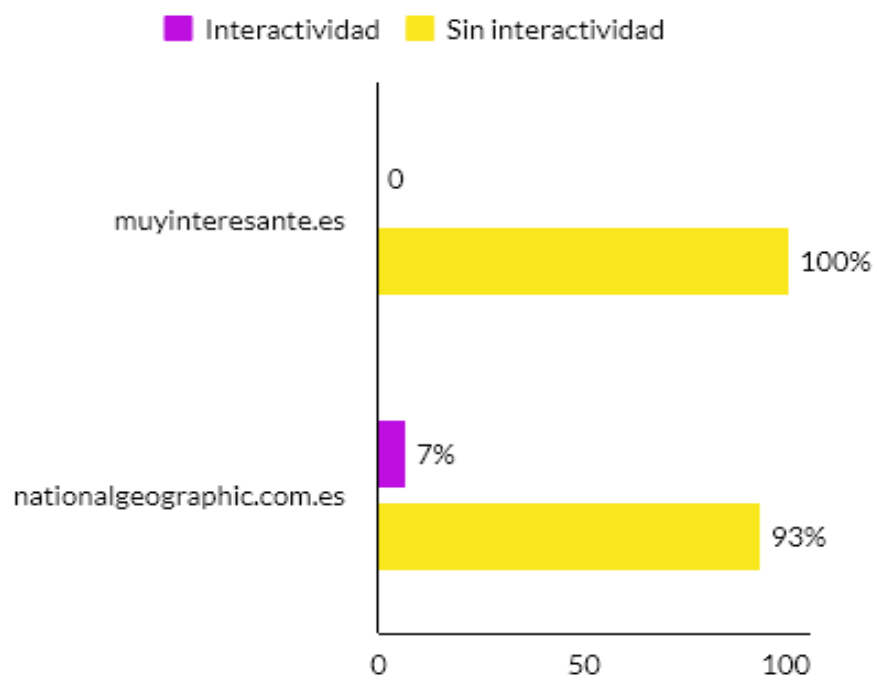

Nota: Elaboración propia.

\subsection{La imagen como interfaz o elemento central}

El siguiente objetivo del estudio es identificar en qué tanto por ciento la imagen es el elemento central de la pieza informativa y no un acompañamiento de la pieza escrita. Y los resultados desvelan una representatividad nula en Muy Interesante y del 15,2\% en National Geographic. Al establecer la correlación entre imagen como pieza central y tipología, los datos desvelan que en un $100 \%$ se usa una imagen fija y en concreto la fotografía. Se destaca que estas piezas, donde la imagen ha sido el elemento central también se han usado para publicarse en Instagram con posterioridad como es el caso de la pieza "Hospitales improvisados" publicado en nationalgeographic.com.es (14/II/2020) y en Instagram (16/III/2020); "La última noche", que se publicó el 13/III/2020 y al día siguiente en 
Instagram (14/III/2020); "Brigada de limpieza" (17/III/2020), publicado el mismo día en ambas plataformas y "Héroes", publicado el 30/III/2020 y el 31/III/2020 en Instagram.

\section{Figura 3}

Diseño de las piezas informativas donde la imagen es el elemento central
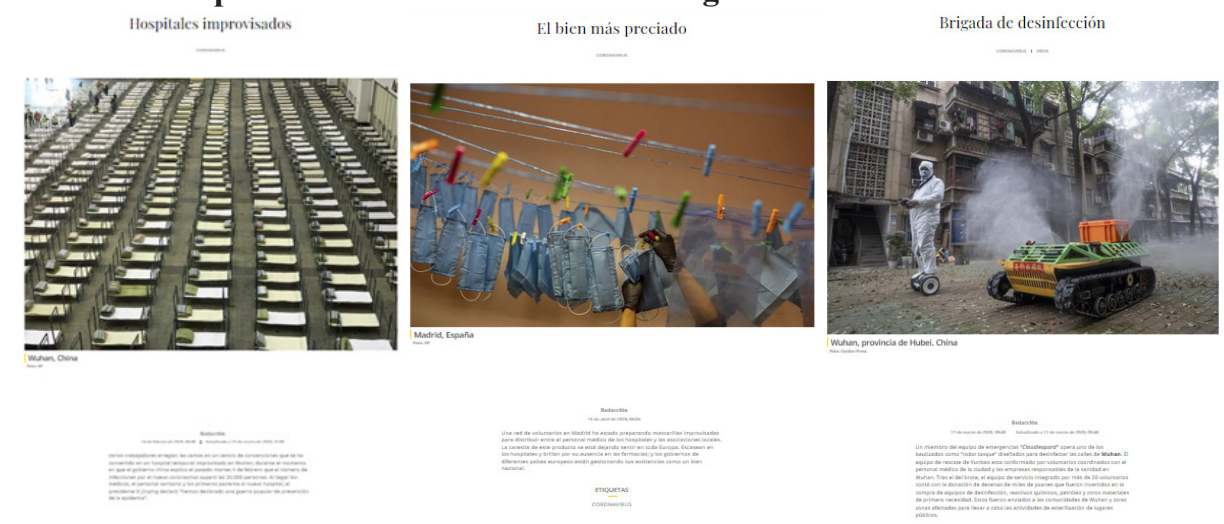

Nota: nationalgeographic.com.es (2020).

\subsection{Autoría de la imagen}

Las fuentes se identifican en la mayoría de las piezas visuales, aunque la disfunción de no identificarla se produce en un 3\% en National Geographic y en $14 \%$ en Muy Interesante. La procedencia de las imágenes se corresponde, en el caso de Muy Interesante, por orden decreciente: banco de imágenes $(77 \%)$, fuentes expertas $(9 \%)$, otros $(8 \%)$, agencias $(2 \%)$, ministerios $(1 \%)$, otros medios $(1 \%)$ y firma de autor $(2 \%)$.

En el caso de la edición digital de National Geographic, las fuentes proceden por orden decreciente de banco de imágenes (66\%); agencias $(3 \%)$, firma de autor (17\%), fuentes expertas (11\%); medios (1\%), buscadores de Internet (1\%) y otras (1\%). Es así que suelen ser los bancos de imágenes los lugares de donde proceden las imágenes en ambas revistas para informar de la COVID-19. Y que las fuentes expertas no tienen una alta representatividad. 


\section{Figura 4}

Procedencia de los contenidos visuales para informar sobre el COVID- 19
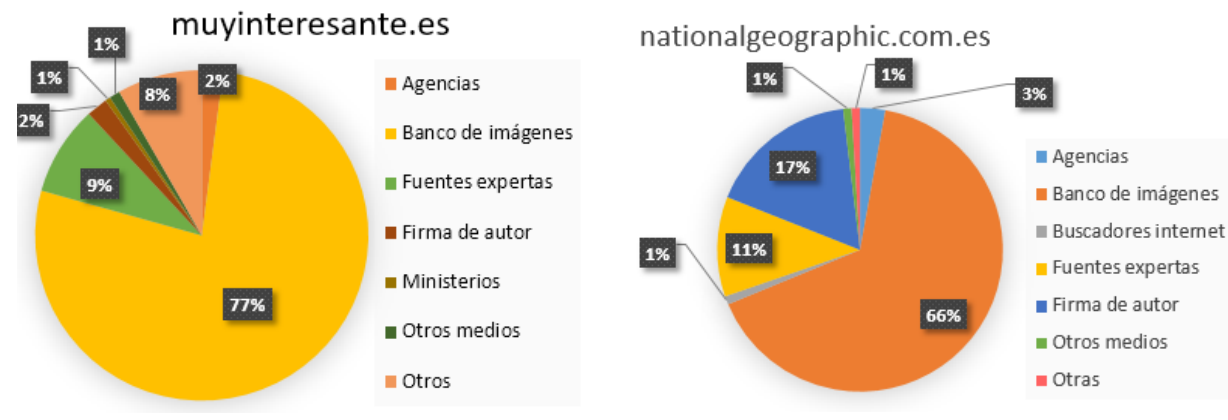

Nota: Elaboración propia.

Si atendemos a la identificación de fuentes no expertas en Muy interesante, los datos indican que proceden de los siguientes bancos de imágenes: istock, istockphoto, depositphoto, pixabay, y getty. En National geographic procede de banco de datos (Istock, graphics RF/Shutterstock); agencias de prensa (Cordon Press y AP); y buscadores (Bing y Google).

La correlación entre autoría y tipología desvela que las fotografías proceden principalmente de agencias de noticias en National Geographic seguida de banco de imágenes y que en Muy Interesante procede principalmente de banco de imágenes. Así como, que las ilustraciones también proceden del banco de imágenes tanto en National Geographic como en Muy Interesante. Sin embargo, los mapas proceden principalmente de fuentes expertas, así como las imágenes microscópicas en ambas revistas.

El resto de imágenes fijas que sólo son usadas por Muy Interesante proceden principalmente de las siguientes fuentes: los gráficos de fuentes expertas y tanto los fotomontajes como las imágenes en 3D de bancos de imágenes. Y se destaca que la única infografía procede del medio de comunicación The Conversation.

\section{Discusión}

Los resultados indican que hay una elevada presencia de la imagen, especialmente de la imagen fija frente a la audiovisual y dentro de esta categoría es la fotografía el contenido visual más usado para informar de las crisis del 
coronavirus (H1). Si bien, no hay estudios precedentes que aborden el uso de la imagen durante la cobertura de una crisis sanitaria en las revistas de divulgación científica, se destaca que si comparamos los resultados con estudios precedentes que lo han analizado en la prensa española estos coinciden tanto en la elevada presencia de la imagen en la cobertura de las crisis sanitarias, como en la alta representatividad de la imagen fija y en concreto de la fotografía tanto en la cobertura de las crisis del Ébola (Catalán, 2014), en la de la gripe A (Camacho, 2009) y en la crisis de la bacteria E. Coli (López Villafranca, 2013).

Si bien, frente a la escasez del uso de la infografía en el estudio realizado, investigaciones previas sí indican que ha sido usada por los diarios tanto en la crisis del Ébola (Catalán, 2014) como en la Gripe A (Camacho, 2009; López Villafranca, 2012), lo que resulta curioso que en una revista de divulgación científica cuya función es atraer y hacer comprensible la información no haya usado este tipo de recurso visual considerado como "una de las más importantes formas de presentación informativa" (Valero Sancho, 2008, p. 492).

Asimismo, aunque hay un elevado uso de contenido visual, la imagen ocupa un menor protagonismo frente al texto porque se inserta como acompañamiento y no como elemento principal o interfaz principal para informar $(\mathrm{H} 3)$, resultado que también coincide con su uso en crisis precedentes en la cobertura informativa de los diarios (López Villafranca, 2013).

El casi nulo aprovechamiento de los recursos de la web para dotar de hipervínculos a la imagen (H4) también coincide con su escasa utilización en otras crisis como la del Ébola (Costa-Sánchez et al., 2015). Lo que implica una deficiencia del escaso uso de los enlaces para contextualizar, explicar, exponer detalles de la imagen, atraer al lector, explicar mejor el contenido de la imagen, "conectar un texto con otro, combinar textos con archivos de sonido, imágenes estáticas y dinámicas, tours guiados, mapas, buscadores, textos adicionales, etc." (Puchmüller \& Puebla, 2008).

Los resultados sobre la autoría de las fuentes, que indican una elevada procedencia de los bancos de imágenes (H2), sí son diferentes a los desvelados en estudios precedentes en otras crisis sanitarias. Si en las revistas de divulgación prevalecen los bancos de imágenes, López Villafranca (2013) concluyó que en la crisis del pepino proceden en porcentajes parecidos de redacción y de agencias. En la crisis del Ébola, Alcibar (2018) indicaba que su proceden- 
cia era de fuentes expertas, las cuales (en el caso del presente estudio) solo se usan para los mapas y las imágenes microscópicas.

Si comparamos los datos de este estudio con otros precedentes centrados en el uso de los recursos visuales en las revistas de divulgación científica, pero en una situación pre-pandémica, nuestros datos corroboran lo expuesto por Bricio (2016) que subraya como las imágenes son meramente ilustrativas y que los recursos visuales no se aprovechan al máximo. Del mismo modo, sucede con Tejedor et al. (2018) que indican un elevado uso de banco de imágenes; una alta presencia de imágenes estándar sin editar; una escasa explotación de datos estadísticos con estrategias visuales y de interactividad en las imágenes, así como escasez de infografías y que los contenidos visuales proceden en un alto porcentaje de los bancos de imágenes. Unos datos que nos permiten interpretar que no se han modificado por parte de estas revistas el modo de informar en tiempos de pandemia, porque presentan las mismas disfunciones y patrones de construcción del mensaje periodístico visual.

\section{Conclusiones}

El objetivo del estudio ha sido analizar el contenido visual en la cobertura informativa del COVID-19 en las revistas de divulgación científica españolas más consumidas durante la crisis del coronavirus y las conclusiones obtenidas son las siguientes:

- La fotografía es la tipología visual más usada. Escaso uso de otros contenidos visuales fijos, así como, de la imagen audiovisual.

- El contenido visual, construido principalmente con una sola imagen, no se construye en base a fuentes sólidas pues la mayor representatividad procede de banco de imágenes que sólo aportan imágenes ilustrativas. Es así que es necesario potenciar los contenidos propios y especializados también en la imagen.

- No se aprovechan las posibilidades de los hipervínculos que ofrece el soporte digital para documentar la imagen fija mediante enlaces para explicar los elementos visuales, redirigir a otros textos o hacer que el lector se fije en detalles que pasan desapercibidos de un primer vistazo 
visual. Por tanto, se trata de una praxis que está anclada en el modelo tradicional de la difusión de la información visual en el formato impreso. No obstante, se destaca que sí usan los recursos digitales para mejorar la visualización de la imagen.

- La imagen acompaña siempre al texto y es muy escasa su presencia como elemento principal. Y cuando, escasamente, se da prioridad a la imagen sobre el texto se siguen usando el mismo patrón para contextualizar la imagen que en el impreso: una imagen fotográfica de grandes dimensiones junto al pie de foto.

- En este contexto, se determina que hay una ausencia de la construcción del mensaje a través de la imagen y que (al igual que se aportan guías para informar con rigurosidad en las piezas informativas) se deben comenzar a establecer las pautas de un periodismo riguroso en tiempos de crisis para optimizar el valor informativo de la imagen para paliar la curva epidemiológica en la sociedad de la información actual, donde prima el consumo visual y el consumo ligero que consiste en leer solo el titular y visualizar la imagen.

- En estudios futuros se pretende realizar entrevistas en profundidad a los responsables de las revistas analizadas con el objetivo de entender los motivos de estas disfunciones, el proceso de producción del mensaje visual y las medidas que se deberían abordar para optimizar la imagen en la cobertura informativa de la actual crisis sanitaria.

\section{Fuentes consultadas}

Alcibar, M. (2018). Information visualisation as a resource for popularising the technical-biomedical aspects of the last Ebola virus epidemic: the case of the Spanish reference press. Public Underst Sci, 27(3), 365-81.

Andreu-Sánchez, C., \& Martín-Pascual, M. (2020). Fake images of the SARS-CoV-2 coronavirus in the communication of information at the beginning of the first Covid-19 pandemic. El profesional de la información, 29(3). https://doi.org/10.3145/epi.2020.may.09 
Bravo, J., Larrea, C., \& Ruales, R. (2020). Tratamiento del Covid-19, Ecuador mediante el humor periodístico. Brazilian Journal of health Review, 3(2), 3423-3541. https://doi.org/10.34119/bjhrv3n2-183

Bricio, A. (2016). Las revistas cientificas digitales: mensajes divulgativos y aprovechamiento de los recursos [Trabajo fin de grado]. Universidad de La Laguna. http://riull.ull.es/xmlui/handle/915/3583

Bucchi, B., \& Saracino, B. (2016). Visual Science Literacy' Images and Public Understanding of Science in the Digital Age. Science Communication, 38(6), 812-819.

Cairo, A. (2011). El arte funcional. Infografia y visualización de la información. Alamut.

Cairo, A. (2013). The Functional Art: An Introduction to Information Graphics and Visualization. New Riders.

Calvo, M. (1992). Periodismo científico. Paraninfo.

Camacho, I. (2009). La gripe A en la prensa española. Revista Latina de Comunicación social, 64, 827-843. https://doi.org/10.4185/RLCS-642009-865-827-843

Catalán, D. (2014). El contenido visual publicado en prensa durante una crisis sanitaria: el caso del Ébola, España. Interface - Comunicacao Saude Educacao, 24(2), 1-18. https://doi.org/10.1590/interface. 190271

Catalán, D. (2019). La importancia del periodismo visual en situaciones de emergencias. Revista española de Comunicación en Salud, 1, 131131.

Costa-Sánchez, C., Rodríguez-Vázquez, A., \& López-García, X. (2015). Del periodismo transmedia al replicante. Cobertura informativa del contagio de ébola en España por Elpais.com. El profesional de la información, 24 (3), 282-290. http://dx.doi.org/10.3145/epi.2015.may.08 
Estudio General de Medios, EGM. (2020, Enero 15). Reporte audiencia general de medios - Evolución penetración audiencia general de medios, http://reporting.aimc.es/index.html\#/main/cockpit

First Draft. (2020, Julio 15). Portal oficial. https://firstdraftnews.org

Harrower, T. (2002). The Newspaper Designer's Handbook. Brown \& Benchmark Publishers.

Herrero, V., \& Rodríguez, A. (2015). Periodismo de datos, infografía y visualización de la información: un estudio de El País, El Mundo, Marca y El Correo. https://dx.doi.org/10.1344/BiD2015.34.5

López Villafranca, P. (2012). Los encuadres sanitarios en prensa española: el caso de la gripe A y la bacteria E. Coli. Revista Internacional de Relaciones Públicas, 2(4), 241-246. http://doi.org/10.5783/RIRP-4-2012-10-221-246

López Villafranca, P. (2013). Los encuadres de la prensa española sobre la crisis sanitaria por la bacteria E. Coli. Anuario electrónico de Estudios en Comunicación Social "Disertaciones", 6(2), 112-144.

Marín, F., \& Armentia, J. (2002). El periodismo científico en los diarios digitales del Estado español. Mediateka, 8, 157-178.

Neuro-com. (2020). Investigación sobre las imágenes del coronavirus SARSCoV-2 en los medios (2020). Universidad Autónoma de Barcelona. https:/www.uab.cat/web/sala-de-prensa/detalle-noticia/investigacion-sobre-las-imagenes-del-coronavirus-sars-cov-2-en-los-medios-1345667994339.html?noticiaid=1345810970323

Organización Panamericana de la Salud, OPS. (2020). Covid-19. Consejos para informar. Guía para periodistas. https://www.paho.org/es/documentos/covid-19-consejos-para-informar-guia-para-periodistas

Pérez Daza, J. (2020). Imágenes, metáforas y representaciones visuales de la pandemia COVID-19. Temas de Comunicación, 40, 33-53. http://revistasenlinea.saber.ucab.edu.ve/temas/index.php/temas/article/download/4598/3834 
Puchmüller, A., \& Puebla, M. (2008). Analysis of the organizational and informational value of links in psychology and geology popular science hyperarticles. Revista Signos - Estudios de Lingüística, 41(68), 423-437.

Ramirez, M., Quesada, M., \& Hernández, I. (2010). Knowledge, attitudes and practices against the dengue by Costa Rican media. Revista Costarricense de Salud Pública, 19(2), 88-92. https://www.scielo.sa.cr/scielo. php?pid=S1409-14292010000200005\&script=sci_abstract

Shin, H. (2016). Epidemic and risk communication: An analysis of strategic and graphic characteristics of infographics [Tesis de maestría]. Iowa State University. https://lib.dr.iastate.edu/etd/15172

Smeesters, D., \& Mandel, N. (2006). Positive and negative media image effects on the self. Journal of Consumer Research, 32(4), 576-582. https://doi.org/10.1086/500489

Tejedor Calvo, S., Portalés-Oliva, M., \& Pueyo Villa, S. (2018). Web 2.0 y tratamiento informativo en las principales revistas españolas de divulgación científica y de la pseudociencia. Revista Latina de Comunicación Social, 73, 293-316. https://doi.org/10.4185/RLCS-2018-1256

Trujillo, H., \& Contreras, F. (2002). Periodismo digital y discurso científico: nuevos modelos para el siglo XXI. Razón y Palabra, 27. http://www. razonypalabra.org. $\mathrm{mx} /$ anteriores/n27/fcontreras.html

Valero Sancho, J. (2008). La infografía digital en el ciberperiodismo. Revista Latina de Comunicación Social, 63, 492-504. https://doi.org/10.4185/ RLCS-63-2008-799-492-504

Welhausen, C. (2015). Visualizing a non-pandemic: Considerations for communicating public health risks in intercultural contexts. Technical Communication 62(4), 244-257.

Wong, N., Harvell, L., \& Anaz, N. (2013). Comparing two modes of presentation on perceptions of flu threat and attributions for its global outbreak. European Journal of Geography 4(2), 17-33. 
Yarnoz, C. (2020, Abril 24). Una narrativa visual para rastrear el virus. El País. https://elpais.com/elpais/2020/04/24/opinion/1587764653_589899. html?ssm=TW_CM 